[This is a submitted Manuscript that has not yet undergone peer review. The Accepted Manuscript has been published in "Framing Peace: Thinking about and enacting curriculum as radical hope" Edited by Hans Smits and Rahat Naqvi in the series 'Complicated Conversation'. The original work can be found at https://doi.org/10.3726/978-1-4539-1376-5 @ [Peter Lang AG,2015] ]

\title{
FRAMING PEACE:
}

\section{THINKING ABOUT AND ENACTING CURRICULUM AS RADICAL HOPE}

\author{
Editors: Hans Smits; Rahat Naqvi \\ Between Being “Acted Upon and Acting” \\ --An Educator's Experience in Framing Peace Through Restorative Justice
}

Author: Dorothy Vaandering

Am I honouring? Am I measuring? What message am I sending? These three questions frame my daily encounter with life and learning. They have made the framing of peace a personal matter. They embody Butler's (2009) challenge to recognize how lives are made precarious through the frames we employ to view humanity, as well as our collective responsibility for nurturing what it means to be fully human. They tap directly into the foundation of this book - to acknowledge our common vulnerability and explore how to transform our melancholia "to forms of mourning that include a "turning, working, cultivating [of] oneself in a different direction"” (White, 2000, p. 100). Through their use, verticality and horizontality of curriculum come to life so that I and my students are better able to "live the educational experience" (Pinar, 2007). 'Currere' becomes a verb so that, as an educator, I am no longer able to teach "about" life but must engage life with my students. As such, the questions constitute a frame of peace that allows me to take up my responsibility as a curriculum writer and practitioner.

Am I honouring? Am I measuring? What message am I sending? continue to challenge and serve me well after years of use. With them I play within and push against the boundaries of the frames of war that Butler describes for understanding the precariousness of life and the frames of peace that Smits \& Naqvi (2012) identify for rethinking the possibilities and responsibilities inherent in curriculum. In so doing, the practical, individual work involved in moving from the conceptual to the moment by moment social experience of education is encountered. The strength and sustainability of the questions come from two qualities that Butler indicate are necessary if a frame is to enhance life: (a) they create an acute awareness that there is something beyond the borders of the frame they construct, and (b) self-breakage and change are part of their composition. This occurs because the questions position me in that space where I must decide if I will contribute to the humanization or dehumanization of others, that inevitable space where Butler indicates peace is chosen (2004, p. 134), where radical violence is replaced first by radical vulnerability (2004, p. 16) and then radical hope (Lear, 2006).

Am I honouring? Am I measuring? What message am I sending? come from my engagement with the philosophical foundations and practice of restorative justice (rj) in educational institutions. Immersed in the practice of $\mathrm{rj}$ as a teacher and researcher, I struggled to understand and articulate its essence till I discovered its origins were rooted in concepts of justice grounded in one's perspective of humanity. The questions emerged because I needed to be able to recognize what was at the core of the practice, if I was not 
to co-opt it with a default understanding of justice that measured everything in terms of right and wrong.

Narrative inquiry examines experience as it is lived through temporality (past, present, future), sociality (personal within the social), and place (location influences experience) (Clandinin \& Rosiek, 2007). In this chapter, I share my lived experience with rj and this frame of questions, illustrating how I am "decentred from my supremacy" by them and challenged "to hear beyond what I am able to hear" (Butler, 2004, p. 18), which is revealing how peace can be fundamental to curriculum theorizing so that my students and I together no longer simply learn about peace but actually begin the experience of living peace.

I begin by providing a brief overview of the origins and contemporary understanding of $\mathrm{rj}$, as well as the manner in which rj is being employed in education. I then outline how Lear's (2006) concept of radical hope and Butler's (2004) questions regarding the precariousness of life overlap with the philosophical foundations of rj. Then, using critical personal narrative, I describe how rj in education became embodied for me through the use of the three questions, as they made obvious the juncture of 'being acted upon and acting' (Butler, 2009). I describe how, at this juncture, I confront what it is to be human; and I am challenged to make conscious decisions for or against the well-being of others, myself and this world which we inhabit.

\section{The Roots of Restorative Justice}

Restorative justice has a history dating back to the earliest of times where people in communities were responsible for addressing the difficulties and harm that arose and impacted them directly. This contrasts with the more recent Western approach where such issues are removed from those directly involved and dealt with by third parties (lawyers) in an institutional (court) context (Christi, 1977). To understand rj's current revival and use within schools, it is important to look at its origins.

Pranis, Stuart, and Wedge (2003) describe in detail ancient and contemporary indigenous traditions where talking circles ${ }^{1}$ are employed as a means for communities to support each other in the complexities of daily living. In these circles, most often led by a community elder, everyone connected to a community concern is given space and time to speak their concerns, questions, and insights into the collective circle as a means for moving forward in a "good way." At the heart of such dialogic approaches is the belief that people are relational beings (Pranis, 2007) who benefit from the collective wisdom of the community and where "we are all in need of help and that helping others helps us at the same time" (Pranis, 2005, p. 6). Hadley (2001) describes how dominant ancient and spiritual traditions (Buddhism, Hindu, Muslim, Christianity, Judaism) share "value systems that provide both the context and the dynamics for integrating individuals into community: for healing, for forgiving and reconciling, for nurturing and fostering responsibility; for restoring individual dignity and peace" (p. 25). Zehr (2005), a

\footnotetext{
${ }^{1}$ As rj has developed, the practice of and term 'talking circles' has become more prominent in nonaboriginal contexts especially when used in schools and communities. They are modelled after/adapted from aboriginal practices.
} 
criminologist who is considered the grandfather of $r j$ in contemporary times, identifies from a Judeo-Christian context how the relational concept of shalom-God's intention for how things are to be among people, between God and people, and even nature (Yoder, as cited in Zehr, 2005, p. 132) — sets the stage for a renewed understanding of justice.

Justice in these contexts is not concerned primarily with judgement and measurement of harmful behaviour, nor with fair distribution of wealth and responsibilities (Rawls, 2001), but rather with insuring that individuals and societies have that to which they have a right - conditions under which their worth and well-being is nurtured (Wolterstorff, 2006). This perspective contrasts sharply with the dominant Western liberal society's emphasis on the individual and the need to control harmful behaviour through punishment that instils fear (Bianchi, 1994; Llewellyn \& Howse, 1998; Van Ness \& Strong, 2006; Zehr, 2005). Justice is not what is put in place for ensuring what 'ought to be' but rather justice is 'the way of being' where peoples' worth and well-being are nurtured.

\section{Restorative Justice in a Contemporary Western Context}

Contemporary rj practices are diverse and growing rapidly within a wide variety of social contexts "looking for constructive ways of dealing with the aftermath of crime, while forming part of a wider socio-ethical and political agenda" (Aertsen, Parmentier, Vanfraech, Walgrave, and Zinsstag, 2013). Although diverse, most proponents would agree that it began by establishing itself as an alternative to conventional, retributive approaches to criminal justice. Zehr (2002) identifies it as "an alternative framework for thinking about wrongdoing [that] requires, at minimum, that we address victims' harms and needs, hold offenders accountable to put right those harms, and involve victims, offenders, and communities in the process" (p. 25). This perspective, Zehr (2005) explains, is rooted in nothing less than a philosophy or worldview that influences how we see ourselves, others, and the world around us (p. 150). As such, in much of the literature, $\mathrm{rj}$ is used interchangeably to describe both this process for addressing harm done within communities and the values for which it advocates - respect, interconnectedness, restoration, and healing (Marshall, 2011).

Early theory describes rj in a judicial context as a paradigm shift that became evident through different questions asked when things went wrong. Instead of, "What rules have been broken? Who did it? What do they deserve?" a rj paradigm asks, "Who has been hurt? What are their needs? What needs to be done to repair the harm?" (Zehr, 2005). This shift was modelled after traditions that are/were used and being revived in aboriginal communities like Hollow Water, Manitoba, (Ross, 2005), and the Maori in New Zealand (Braithwaite, 2002; MacRae \& Zehr, 2011). Such alternative dispute resolution programs, community justice panels, sentencing circles, etc. all worked to keep the issue at hand in the hands of those directly involved, as a contrast to adversarial justice where third parties take over (Christie, 1977). In general, processes were developed where facilitators brought together into formal meeting or talking circle those who had been harmed, those who had caused the harm, their supporters, and others who were impacted by the event more peripherally, so they could share their stories, describe their needs, and bring forward suggestions that would bring about healing. 
The healing and hope that tentatively emerged from these experiences in the 80's and 90's spurred on the implementation of $\mathrm{rj}$ in alternative schools for youth convicted of crime. In 1995, Ted Wachtel, in conjunction with Terry O'Connell in Australia, introduced the rj process into a school in Pennsylvania (Wachtel, 1997). Here, formal conferences were employed when students were in conflict with each other or transgressed school policy. As in the judicial context, these circle conferences involved having those who caused harm, those harmed, those impacted by the incident, and their supporters (i.e. parents, peers, teachers, administrators, or mentors--people who cared for them), sit in a circle with a facilitator who guided dialogue with a framework of questions (Wachtel, 1999), such as:

Those causing harm:

What happened?

What were you thinking about at the time?

What have you thought about since?

Who has been impacted by this? How?

What do you need to do to repair the harm?
Those harmed and affected:

What was your reaction at the time of the incident?

How do you feel about what happened?

What's been the hardest thing for you?

What do you need in order to go on?

Such questions allowed for each person to share their story and work together as a group to repair the damage caused and rebuild relationships that had been broken through the harm caused. When the telling of each story is facilitated carefully, participants came to see the incident through the frames of other people's lives. As all of these stories meet in the space provided, a moment of collective vulnerability (Moore, 2004) occurs where empathy is established and, together, participants work to resolve the issues that have arisen.

Educators discovered that this process for addressing harm also encouraged the development of more cohesive, supportive school cultures, as relationships amongst and between students, as well as students and teachers, grew stronger. Recognizing this as significant for any educational context, rj was introduced to mainstream schools in an effort to replace punitive managerial structures of schooling with those that emphasized the building and repairing of relationships (Hopkins, 2004). In many cases, significant changes occurred (Porter, 2007). As such, rj was offering a critique and alternative to previous and current safe school and anti-violence policies that use various exclusionary measures to manage student behaviour. To understand how and why this approach had such an impact, the foundation of rj was and is being explored, so that theory now includes the examination and development of relationship-based cultures (Morrison, 2007; Hopkins, 2011) that are built on a foundation of justice that is comprehensive in nature and involves honouring the worth and working for the well-being of all (Wolterstorff, 2012; Zehr, 2005). As a result, in the context of schooling, rj has grown to be understood not as a means for social control that focuses on changing student behaviour, but one that focuses on social engagement that involves all students and adults within the school experience as they seek to build, maintain, and repair relationships with each other, the community, and the curriculum (Morrison, 2012). At this level rj is informed and deepened by the insights of Lear (2006) and Butler (2004, 2009).

\section{Restorative Justice in the Context of Butler and Lear}


The philosophical questions Lear, Butler, and proponents of rj grapple with overlap in their effort to identify what it is to be human and the role shared vulnerability takes in determining human value. Lear (2006) examines the collapse of the Crow culture through Plenty Coup's statement, "after this, nothing happened" (p. 2) . Lear recognizes the essence of life in the use of the word 'nothing,' as the Crow people continued to live physically and actively after the buffalo left, yet could/would not articulate that life as significant. Butler (2009), in her examination of the precariousness of life in the context of war, asks, what is a life? Like Lear, this question drills into determining when life is being lived and when it can be dismissed by ruling powers and those holding weapons of destruction. Early theorists in rj (Bianchi, Zehr, and Pranis) worked to identify why justice must be understood more broadly than justice as right-order and fairness (Rawls, 2001) to encompass the inherent rights of all people (Wolterstorff, 2008) and ensure they are liberated from "repression, fear, alienation, and exploitation" (Bianchi, 1994, p. 26). In my exploration of the differing conceptions of justice, I began to realize that these were embedded in one's perspective of humanity and began to ask, "What does rj presume about being human?" In so doing, I confronted the fact that, as a teacher, as a human being privileged to be part of a dominant culture, and now a proponent of rj, I was living out of assumptions of what it was to be human. And this, I came to see, had serious implications for what I taught, how I taught, and how I engaged with students and colleagues.

In grappling with what is a life, what is the essence of life, and what is it to be human, Lear, Butler, and proponents of rj engage with the concept of 'shared vulnerability' Lear (2006) considers what it is to live with the possibility of collapse that is beyond the control of the individual or a culture but is at the mercy of others or an environment that removes that which is life sustaining. Butler sees the precariousness of life when a life is not "recognized" as valued, when there is no frame that gives that life meaning (2009, p. 7). This doesn't negate that life exists; however, without a frame created by the norms of a society that allow life to be recognized, life can be taken without concern (i.e abortion, euthanasia, genocide, war zones). At what point are such decisions made? Pranis and Zehr's belief that human beings are relational, and Wolterstorff's explanation that human beings are to be honoured as worthy regardless of their station in life, infer vulnerability and point to the potential for dehumanization when life is separated from its social context or not honoured. Lear (2006, p. 4) and Butler (2004, p. 140) both engage with this concept of humanization and dehumanization in how we are perceived by others. To understand more fully the honouring of and working for the well-being of all through rj, I turned to Freire's (1970) concept of humanization. He focuses attention on how being human is to accept our vocation of becoming more fully human-- a process where individually and collectively we need to recognize people as being alive, organic, and in a constant state of change where life can be enriched. This he contrasts with a person's loss of humanity that occurs when one accepts what an oppressive power has convinced them of -- that they are objects existing merely to serve the needs and desires of the powerful so that they can maintain their dominance. This language of being objectified hit home for me.

I began to reflect-do I ever feel like an object? When am I objectified and used? When do I feel like I am becoming more fully who I feel I have been made to be? These simple 
questions shook my world as I discovered that, even in my privileged context, consciously or unconsciously, I was subject to being objectified by both myself and others. In my desire to belong, I questioned if I looked like people wanted me to look, if I did what others wanted me to do, if I said the things that would give me value so that those in power would protect me. I caught a glimpse of the precariousness of life, the fine line that nurtured or diminished who I knew myself to be internally. When I considered others whose circumstances were more challenging than mine, not only did the reality of objectification come clear, but my complicity in objectifying others came to the fore. As I searched to understand how to become more fully aware of when I was being objectified or when I was objectifying, I contrasted justice as a means to measure and judge an individual to justice as a means for nurturing relationship and life. These three questions emerged: Was I being measured? Was I being honoured? What message was I receiving from others? And then quietly, I also asked, Am I measuring? Am I honouring? What message am I sending? In using them, I found myself standing at a juncture, a place where I could choose to nurture or diminish my own life and the lives of others.

In Precarious Life, Butler (2004) insightfully identifies this place as the juncture of being acted upon and acting.

Both the discourse of individualism and moralism assumes that the individual is the first line in a causal chain that forms the meaning of accountability. But to take the self-generated acts of the individual as our point of departure in moral reasoning is precisely to foreclose the possibility of questioning what kind of world gives rise to such individuals. ... to ask these questions is not to say that the conditions are at fault rather than the individual. It is rather to rethink the relation between conditions and acts. Our acts are not selfgenerated, but conditioned. We are at once acted upon and acting, and our responsibility lies in the juncture between the two. (Butler, $2004, p .15,16)$

Butler assigns no fault to either the discourse of individualism or its context. Instead, she accepts the reality of both and moves between them to discover space and opportunity for personal and communal response. She echoes this in her later discussion of how the ontology of a body is a social ontology where "the body is exposed to the socially and politically articulated forces as well as to claims of sociality ... that make possible the body's persisting and flourishing" (2009, p. 3). As rj engages with a perspective of justice that honours the worth and works for the well-being of all, acknowledging the individual in the context of society is central. This is illustrated in the context of a circle conference organized to resolve the impact of harm done. Unlike mediation where the parties directly involved meet with a mediator to come to agreement or compromise, a rj circle brings the individuals directly involved (i.e.those who caused harm and those harmed) together with others impacted by the harm through personal association (i.e. parent, friend, relative) and through association with the event (i.e. vandalism/theft of property). As each shares their story of how they came to be involved or impacted, each is led to that juncture where they become aware of how they are being acted upon and acting. The point at 
which participants are awakened to the reality of others is what Moore (2004) calls the "moment of collective vulnerability" (p.78). Here, each begins to understand how the one causing the harm has been shaped by his/her circumstances to act out. The one causing harm sees how his/her actions have, through a ripple effect, impacted lives in ways they never imagined. Blame dissipates as people realize the complexity of the situation and that everyone inherently wants life to be nurtured. Together they work to find ways for all aspects of the harm to be repaired.

As I came to understand what happens in such circles, the relationship between the bodily ontology and the social ontology became more apparent, so that the juncture was not only evident when people were together to resolve and repair harm, but in every decision I was making in life. Thus, our responsibility at this juncture is crucial. Freire (2000) indicates this to be our vocation; because it is here, in our on-going choices not to objectify self or others, we become more fully human Butler (2009) echoes this: "every construction of life requires time to do its job" and the "the job is never done "once for all"" (p.4). Thus, to take up this on-going responsibility in an active manner, I have found the questions, Am I honouring? Am I measuring? What message am I sending? invaluable. When we stand at this juncture, alone or with one whose life has been negated, pose these questions; and we choose to honour life, our view is enlarged as the frame is reconstructed. This is "peace as the awakeness to precariousness of the other" (Levinas, in Butler, 2009, p. 134).

The following narratives illustrate the significance of these questions as a frame for peace in the context of schooling. They also demonstrate how Smits and Naqvi's (2012) challenge can be taken up ... "what is a life? is, or should be, a central concern for curriculum practice and theorizing," so that, as educators, we can live hopefully in a world that is always out of joint, "challenging the frames that underlie our approaches to students, language, and learning" (p. 14).

\section{Our Common Vulnerability Acknowledged -The Meaning of the Questions}

Chris was home from school again. The school in which I taught, and in which my two sons were students, was not exempt from zero-tolerance policy changes that were a reaction to the Columbine and Taber shootings. Suddenly, what were once incidents described as "rough-housing" and addressed with in-school disciplinary measures, became punishable with suspensions and expulsions. My oldest, who was not averse to such roughhousing, when in grades 7 and 8 found himself at home on several occasions when he should have been (and wanted to be) at school. As parents, we did not take these events lightly. What surprised us, however, was the impact these suspensions had not just on our son, but on us as a family within a broader community. Though we were very cognisant of our son's need to take responsibility for the harm he caused, we struggled when we saw how the stigma of being suspended impacted his relationship with his peers, and how he was not guided in his re-entry into school, other than to have a meeting with the principal who issued a stiff reprimand for not doing 'it' again. This stigma reached to 
us as a family - to his younger brother, to myself as a teacher in the school, and to his father, who worked from home. As part of a tight-knit faith community, news of such suspensions often became public knowledge, with varying results. In trying to address some of these concerns, we were most frustrated with having no avenue for resolving the issues and rebuilding affected relationships. Assumptions and unfounded impressions proliferated. We felt judged, jostled about, pushed. We experienced belonging as conditional.

My early involvement with peacemaking education was as a teacher directing the learning of others. As my children engaged with schooling, the impact of school policy and practice hit home. To address the gaps I felt as a parent, I explored the concepts of rj and found them helpful. Yet, I continued to explore them predominantly from the vantage point of teacher - a power position. Gradually, they became more personal; and I grappled with terminology to better understand what was happening.

The terms measuring and honouring in the questions were chosen to allow me to break from presumptions associated with more familiar terms such as judging and respecting. Measuring directed my focus away from the judicial context of rj and towards the school's emphasis on student behaviour and achievement. Measuring challenged me to question if I was viewing my students and colleagues through a lens that turned them into objects that only had value when they fit within social norms, grade level expectations, or my own personal expectations of them. Honouring challenged me to consider the humanity of the one I was with in a more deeply relational way than when I tried to be respectful. Honouring challenged me to question not only if I was accepting of who others were regardless of their appearance, accomplishments, or station in life, but was I also contributing to their well-being. What message am I sending? required that I do my best to consider my engagement with them from their standpoint. My best of intentions, I realized, could be misconstrued when experienced within a life that was not my own.

I woke up to being acted upon when Chris was suspended. Life felt shaped by the whim of others, and my response would impact others. It was difficult to articulate this sense of vulnerability (Lear, 2006, p. 7). Honouring and measuring seemed to help me identify when life was being sustained.

Andrew was one of seven young people who was charged with causing his school lockdown after an adult neighbour chased him and six friends into school shouting, "Those kids have weapons." The event occurred in October, 2007. Each was expelled, charged, and ordered not to communicate with their peers till the case came to court. In May 2008, two days before their court appearance, they sat together in a circle of 35 people who had all been impacted by the event, including, their parents, teachers, students who sat huddled in classrooms waiting during the lockdown, and two facilitators. For the first time in eight months, the friends had opportunity to meet and tell their story. In spite of much misunderstanding that day, they each took responsibility for their role and then described the turmoil of the past months. They listened as the others in the circle then shared how they had been impacted. A sense of collective vulnerability and responsibility emerged. Together they brainstormed for ways to repair the harm done. As the meeting ended, all participants left the circle and came together 
with tears, hugs, and apologies. I sat on the outside, having been given permission to observe. At the outset, I was introduced briefly as a graduate student researching rj in schools. I slipped away quietly onto a well lit school parking lot. As I walked slowly through the night air, I heard a voice behind. "Excuse me." It was Andrew. "Ms. Vaandering, thank you for being here and watching. I'm glad you are researching this. Please do what you can to let people know how important rj is. It has made all the difference." Andrew had been honoured.

\section{Transforming Our Melancholia to Include "Cultivating Oneself in a Different Direction" -The Impact of the Questions}

I pressed the stop button on the dvd player, pleased with the excerpt from the video I had chosen to illustrate the practice of rj for my colleagues. I was presenting my proposal for research to colleagues, excited to be demonstrating what I had tried to describe so often- a practice that held potential for addressing harm in schools. Ready to discuss the details, Lisa's comments came first and cut through my excitement: "I don't get it. It seems to me this is just another way to control student behaviour. It's still about what the teacher needs, not the student." I tried to explain but realized I had only looked at the practice from one vantage point. Lisa's perspective sharpened the view. The bubble of potential burst as I felt myself and the field of rj complicit in perpetuating cultures of control and fear, not relationship and hope.

I pursued rj from the perspective of trying to understand personal loss that had come at the hands of other people's insistence to dictate right and wrong for me in the context of my job and community. Looking from the outside in, few suspected or cared to recognize my grief. I acknowledge its insignificance in comparison to the precariousness of life in war-zones, yet the unmistakable feeling of being snuffed out was real. I felt myself clawing at and life, using rj. Hope began to emerge till I was challenged through Lisa's question to see my role as educator for the power position it was, a position that I had not seen as having potential for oppression. And suddenly the hope I felt in engaging with rj also went dark.

I needed something to use to prevent me from co-opting what I had begun to understand as a "good way" forward. In my early research, I had assumed and presumed much about the term justice ${ }^{2}$. As I pondered the definition of justice as honouring the worth and working for the well-being of all, the three questions emerged. Initially, when using the third person (Are you honouring ....), they allowed me to focus in on the essence of the practice of others and revealed how rj was often being co-opted by well-meaning educators. But when I posed the questions in the first person, I began to dismantle the grip $I$ was holding that also contributed to the co-opting. Not until I used them for myself did I feel that distinct space between being 'acted upon' and 'acting.' In this location, I

\footnotetext{
${ }^{2}$ For a detailed discussion of this struggle to understand the term justice in the context of rj see Vaandering, D. (2011). A faithful compass: Rethinking the term restorative justice to find clarity. Contemporary Justice Review, 14(3), 307-328. doi:10.1080/10282580.2011.589668
} 
was faced with a choice that opens up what Butler (2009) calls a new bodily ontology that is a social ontology:

...if we are to make broader social and political claims about rights of protection and entitlements to persistence and flourishing, we will first have to be supported by a new bodily ontology, one that implies the rethinking of precariousness, vulnerability, injurability, interdependency, exposure, bodily persistence, desire, work and the claims of language and social belonging. (p. 2)

The questions brought me to the place where I could know myself more fully and make choices that I could consciously understand were not causing harm for others.

I stood before the bathroom mirror 6:00 AM in the morning. The subconscious morning ritual began. "You're a mess. You are so ugly. How will you turn you into something presentable for the day's work. " I looked at my wrinkles magnified in the bathroom light, crooked teeth, and disheveled hair that when washed and dried would only sit flatly on my head to accentuate my long face. My mind raced ahead to the work I would present at 10:15. It was obviously inadequate for the needs of the project. I was not ready. I am never ready...

About to enter the shower, I turned and once again glanced in the mirror. Audible words echoed against the porcelain fixtures of the room and within my head, "Dorothy, are you going to honour yourself today or are you going to measure yourself?" The familiar questions I had composed to explore the implementation of rj in schools and teachers' lives suddenly became personal. I stood silent. As tears welled up, I reluctantly spoke the words, "I will honour me today."

\section{The Curriculum as Lived Experience-The Questions Guide My 'Way of Being”}

I have taught primary/ elementary grades for 20 years; recently, I began teaching preservice and graduate education students here at MUN. I begin each class with a circle. Forty students get out of their desks, stand around the periphery of the classroom, and share a few words in response to a topic such as: What's your favourite junk food?; What kind of a vehicle are you today?; or What's on the top of your mind? It takes about four minutes. Some students roll their eyes at first, others wonder what is going on, but all participate, even when they know they can pass if they want to. Half way through the course. I have heard from several students that though they have taken classes with these peers for several months already. This is the first time they feel like they actually are getting to know each other. In a final reflection, Suzanne states:

"The one thing that I loved most about this course was the check-in circle. Initially, I thought checking in every morning was going to be very time-consuming when I just wanted to learn how to teach Social Studies. Reflecting back on it now, I have learnt a lot 
through them. I have learnt about my peers but also learnt how to accept people's views; and, rather than judging, I found myself wondering a lot of why they thought that way."

To live educational experience (Pinar, 2007) that is cognisant of curriculum as situated within historical and contemporary contexts is complex. Breaking from schooling's default practice of transmitting knowledge (Freire, 2000) in order to engage with transformational teaching and learning, I found easy to say but difficult to enact. However, as I engaged with the principles of rj, I used the questions, "Am I honouring? Am I measuring? What message am I sending?" to interrogate the content and pedagogy I was employing. The significance of interconnectedness and relationship became evident, and very quickly foundational changes occurred. My pedagogy of telling shifted to one of asking open-ended questions. I noticed how curriculum content seemed to contradict how we were interacting as a class. Many math story problems promoted individualism that focused on personal gain instead of communal good. Social studies units on countries around the world highlighted the wonders of the environment and the neediness of people. Canada emerged as a developed, first-world country superior to others, and my students claimed their citizenship in it. This was further reinforced when John Cabot was given far more attention than Donnacona and his sons, and when we gave attention only to news articles about the devastating conditions in First Nations communities rather than the positive things that were occurring.

In every subject area and integrated unit, firmly established contradictions were revealed by what was developing amongst us as a classroom community. Hidden curriculum, which I understood theoretically, suddenly came out of hiding. When, as a class, we examined what it was to be human and the conditions we needed to thrive, we were able to discuss the reality of oppression for others and the environment through an understanding of honouring and measuring. These concepts are embraced within Pinar's verticality and horizontality (Pinar, 2007) and create a frame that promotes peace and radical hope because of its willingness to engage with what is a life? (Butler, 2009; Smits $\&$ Naqvi, 2012) in such a way that it permeates all of life- past and present, inside and outside of school, in person or in learning about others - a way of being.

Terri, the grade 6 teacher, explains that on Friday afternoon Bryan karate chops Cody's neck. Cody is hurt and cries. Bryan is asked to go to the office. As soon as he leaves, a flood of emotion comes from the class. Apparently, Bryan has been very explicit with sexual comments directed to the girls, in particular, but also with the boys. His comments indicate that, at the least, he has been exposed to pornography. Apparently, his peers were trying to solve it on their own, but when this happened they realized Bryan was overstepping his boundaries. Terri, brought the students into a circle and asked each to share any details they needed to. At one point, she realized the principal should be present to hear the things being said. Barb came immediately, explained she was there to listen, and allowed for each person to have a say. The kids were very open. Barb then thanked the students for their input. Stan gave the concluding comment, "I just want everyone to know that I've known Bryan since he was little and, really, he is a good guy. He just got into some trouble now." 
Terri smiles. She is thankful for the support he is giving Bryan.

Bryan's parents are called. Both are upset. Together with Barb they make a plan for moving forward that includes an appointment with a service agency in town. They decide that Bryan will need to spend his days in the office till an appointment is made.

Terri and Barb are prepared to respond restoratively to the Grade 6 students at a moment's notice. Student concerns are heard, and they are provided with a space and time in which to share their stories of the pain and harm. The adults do not doubt the students' stories and indicate that Bryan's needs will also be attended to. Bryan's suspension from school is framed in his need for help and the students' need for assurance of safety. Bryan returns to the classroom a week later in the care of Barb and Terri, who provide those hurt with an opportunity to dialogue with Bryan face to face.

A rj circle is set up. Barb explains how all the details weren't going to be brought up again, but each person would be invited to share how they were feeling when Bryan had said things to them or made gestures that were difficult for them. Terri explains how "it just felt really right that they could say to him things like, "disgusted, sick to my stomach, frightened"...those were just really powerful words for a kid to have to listen to. They told it from out of the mouth of a 12 year old. Bryan cried and said he was really sorry." Barb was kind and nurturing with him and at the end took him out. He gathered himself and came in after recess. The other children were upset that he cried and had a discussion with Terri about how it's okay to cry and how that means something. It would be worrisome if he didn't cry. Bryan comes back to class, and his peers are still his friends. If he regresses again, it will indicate how deep-rooted the problem is; and Barb and Terri accept the responsibility that they will need to find more ways to help him heal.

\section{A sustainable frame of peace}

Am I honouring? Am I measuring? What message am I sending? create a frame of peace in that space between being 'acted upon and acting' (Butler, 2009) that allows for radical hope to take hold. Lear (2006) explains this hope as an accomplishment that avoids despair and requires wading into the unknown and waiting (p. 100). When I choose to honour another in such a way that they experience being honoured in school or outside of it, I cannot know the outcome, as their response is beyond my control. It might not fit within the frame, as I know it; I become aware that I must expect the result to be outside of the borders. Like Plenty Coup, I must wait and anticipate that out of the 'after this nothing happened' will come something I cannot know at the moment. Because life is organic, always changing, this unknown requires trust and an expectation that I allow the breakage and reassembly of my frame to occur. When my frame breaks, I again choose to honour the other because of our common humanity and vulnerability. A new frame emerges. Deep peace dispels fear and despair. 
Aertsen, I., Parmentier, S., Vanfraechem, I., Walgrave, L., and Zinsstag, E. (2013). An adventure is taking off. Why Restorative Justice: An International Journal. Restorative Justice: An International Journal, 1(1).

Bianchi, H. (1994). Justice as sanctuary. Bloomington, Indiana: Indiana University Press.

Braithwaite, J. (2002). Restorative justice \& responsive regulation. USA: Oxford University Press.

Butler, J. (2004). Precarious life. The powers of mourning and violence. London: Verso.

Butler, J. (2009). Frames of war. When is life grievable? London: Verso.

Christie, N. (1977). Conflicts as property. British Journal of Criminology, 17(1), 1.

Christie, N. (2013). Words on words. Restorative Justice: An International Journal, 1(1).

Clandinin, J., and Rosiek, J. (2007). Mapping a landscape of narrative inquiry:

borderland spaces and tensions. In Clandinin, J. (Ed.), Handbook of narrative inquiry:

Mapping methodology (pp.35-75). Thousand Islands, London, New Dehli; Sage.

Freire, P. (2000). Pedagogy of the oppressed (30th ed.). New York: Continuum.

Hadley, M. (Ed.). (2001). The spiritual roots of restorative justice. Albany, New York: State University of New York Press.

Hopkins, B. (2004). Just schools: A whole school approach to restorative justice. London: Jessica Kingsley Publishers.

Hopkins, B. (2011). The restorative classroom: Using restorative approaches to foster effective learning. London: Optimus.

Lear, J. (2006). Radical hope: Ethics in the face of cultural devastation. Cambridge: Harvard University Press.

Llewellyn, J., and Howse, R. (1998). Restorative justice--A conceptual framework. Ottawa: Law Commission of Canada. 
MacRae, A. and Zehr, H. (2011, July 8). Righting wrongs the Maori way: Instead of prison, New Zealand chooses restorative justice and community problem-solving. Yes! Magazine, Retrieved from: http://www.yesmagazine.org/issues/beyondprisons/righting-wrongs-the-maori-way

Marshall, T. (2011). Restorative justice: an overview. In G. Johnstone (Ed.), $A$ Restorative Justice Reader: Texts, Sources, and Context (p. 28-45). New York: Routledge.

Moore, D. B. (2004). Managing social conflict--the evolution of a practical theory. Journal of Sociology \& Social Welfare, 31(1), 71-91

Morrison, B. (2007). Restoring safe school communities. Sydney: Federation Press.

Morrison, B. (2012). From social control to social engagement: Enabling the "Time and Space" to talk through restorative justice and responsive regulation. In R. Rosenfeld, K. Quinet, \& C. Garcia (Eds.), Contemporary issues in criminology theory and research. Florence, KY: Wadworth.

Naqvi, R., and Smits, H. (Eds.). (2012). Thinking about and enacting curriculum in "frames of war". Lanham: Lexington Books.

Pinar, W. (2007). Intellectual advancement through disciplinarity: Verticality and horizontality in curriculum studies. Rotterdam: Sense Publishers.

Porter, A. (2007). Restorative Practices E-Forum: Restorative practices in schools: Research reveals power of restorative approach, part I and part II. Retrieved from http://umaine.edu/peace/files/2011/01/RSP_Data_Articles_2.pdf

Pranis, K. (2005). The little book of circle process: A new/old approach to peacemaking. Pennsylvania: Good Books.

Pranis, K., Stuart, B., and Wedge, M. (2003). Peacemaking circles: from crime to community. Minnesota: Living Justice Press.

Rawls, J. (2001). Justice as fairness: a restatement. Cambridge, Massachussetts: The Belknap Press of Harvard University Press.

Ross, Rupert (2005). Aboriginal community healing in action: The hollow water Approach. In Wanda D. McCaslin (Ed.), Justice as healing: Indigenous ways. Writings on community peacemaking and restorative justice from the Native Law Centre (pp. 184-189). St. Paul, MN: Living Justice Press.

Van Ness, D., and Strong, K. (2006). Restoring justice: an introduction to restorative justice (Third ed.). Dayton: Anderson Publishing. 
Wachtel, T. (1999). SaferSanerSchools: Restoring community in a disconnected world. Retrieved from: http://www.iirp.org/library/safersanerschools.html.

Wachtel, T. (1997). Real justice. Pipersville, Pennsylvania: Piper's Press.

White, S. (2000). Sustaining affirmation. The strengths of weak ontology in political theory. Princeton and Oxford: Princeton University Press.

Wolterstorff, N. (2006). Teaching justly for justice. The Journal of Education \& Christian Belief, 10(2), 23-37.

Wolterstorff, N. (2008). Justice: rights and wrongs. Princeton: Princeton University Press.

Zehr, H. and Mika, H. (1998). Fundamental Concepts of Restorative Justice Contemporary Justice Review. 1: 47-55.

Zehr, H. (2002). The little book of restorative justice. Intercourse, PA: Good Books.

Zehr, H. (2005). Changing lenses: A new focus for crime and justice. Waterloo: Herald Press. 